\title{
Ethical issues in regenerative approaches in neonatology
}

\section{Introduction}

At the present time, regenerative therapies using stem cells are theoretical options as alternative treatments in perinatal diseases. These are promising in fields such as inflammatory cascade or regenerative capacity in CNS and lung, but have also been considered in genetic diseases and malformation syndromes. However, there is still no agreement, and applications in neonatology are in the field of research yet. ${ }^{1,2}$

The optimism that comes with technological advances and knowledge about the qualities of stem cells have generated an extensive and complex debate on the limits that this kind of science can have. Since early, research and experimentation with stem cells have triggered various ethical discussions and controversies, especially when it comes from the methods needed for obtaining them, in which, the embryonic origin is the most questioned aspect. ${ }^{3}$

Currently, interventions in this field are based on the use of adult tissue-specific cells or somatic mesenchymal stem cells (MSC) since they do not pose, in principle, more ethical conflicts than those related to the informed consent of the person from whom the cells are extracted. This contrasts with the observed in the so-called therapeutic cloning where there is a later manipulation of embryonic stem cells. These cells have the ability to generate any differentiated cell in the body (pluripotent), those who oppose have argued that it is an illicit intervention. The main argument against the use of this type of cells is that theoretically, fertilization may have been performed for the sole purpose of achieving an embryo from which to obtain this material. Subsequent cytological management is also under discussion. The development of culture embryonic cell in vitro aims to overcome this ethical dilemma. ${ }^{4}$

The therapeutic benefits, until now, are potential. The Mesenchymal Stem Cells (MSC) ability to self-regeneration and pluripotency convert them in an interesting option to provide regeneration and replacement in encephalon and damaged lung, yet oncogenic risk must be considered..$^{5,6}$ Successful differentiation of MSCs to different types of cells like cardiomyocytes, myocytes, endothelial, and epithelial cells has been achieved. ${ }^{7-9}$ In addition, cells capable of express one type of cell can differentiate themselves to others, that occurs with MSCs which differentiate to neuroglias and pneumocytes. ${ }^{10-14}$ Nevertheless, much remains to be known about the factors capable to affect the proliferation and differentiation of these cells including growth factors and proteins of the intercellular matrix..$^{15}$ The study of the therapeutic benefits of MSCs in preterm infants is based on the efficacy demonstrated in animal models. ${ }^{16}$ The applications in children with BPD are the most studied therapies from a variety associated with stem cells. ${ }^{17}$

Other therapeutic benefit of MSCs is its immunomodulatory role. ${ }^{18}$ Besides their regenerative potential, they can modulate the innate and acquired immune response in addition to an anti-apoptosis effect. In this sense, they can decrease inflammation and increase tissue repair through a paracrine effect. ${ }^{19,20}$ This last mechanism has been suggested when analyzing lung graft rates using MSC. ${ }^{21}$ Due to all
Volume 10 Issue 2 - 2018

\author{
Villalon-Urrutia Hernan MD, ${ }^{1,2,3}$ Rosenberg- \\ Pacareu Javiera' \\ 'Servicio de Neonatologia, Clinica Las Condes, Chile \\ 2Profesor Agregado de Pediatria, Universidad de Chile, Chile \\ ${ }^{3}$ Docente invitado de Pediatria, Universidad Católica del Norte, Chile
}

Correspondence: Villalon-Urrutia Hernan, Servicio de Neonatologia, Clinica Las Condes, Chile, Email hpvillalon@gmail.com

Received: February 28, 2018| Published: March 16, 2018

these potential benefits, many clinical studies and animal models have been recently conducted with aims of evaluate possible regenerative effects in the lung and brain. ${ }^{22,23}$

It is important to consider that there has been evidence of nonbeneficial results in the therapeutic use of MSCs, as in cases of pulmonary embolism with endothelial damage when administered intravenously in the treatment of myocardial infarction. ${ }^{24}$

It seems that the potential for immunomodulation and protection of stem cells after an injury, depends on bidirectional communication between damaged and grafted host cells through the exchange of specific information, rather than a direct effect of MSCs. ${ }^{25}$ In fact, stem cells do not directly secrete growth factors and cytokines, but stimulate growth and supplement host cells. ${ }^{26,27}$ Epigenetics is another factor to consider, in which the tissue microenvironment would be important. ${ }^{28}$ Finally, when asked about whether the factors secreted by MSCs or by host cells represents the great alternative for lung and CNS therapy in the newborn, the answer is not clear and the discussion is still open. ${ }^{24}$

From a psychological perspective, medical and technological advances in Neonatology challenge the supporting role required to guide parents, especially when facing questions about vulnerability and guarantees ("life insurance") that these advances promise in their children. Thus, a reflection is needed, mainly when those are offered in the context of delivery, in which the obtaining of umbilical cord cells and/or placental tissue is relatively easy.

The evidence, still incomplete about multiple benefits, should motivate a thorough informed consent considering the economic cost that this implies for the parents. For these reasons, as long as the discussion is kept on a hypothetical level and without a full scientific backing, caution should be taking to avoid encouraging expectations. These could be unrealistic, especially when dealing with situations of psychological vulnerability, as it is to face a painful reality resulting from a chronic disease and poor prognosis in a child. 
Today, one of the main obstacles in addition to the limited access to this type of treatment and high costs, is the lack of clinical evidence for stem cell transplantation in pathologies different from leukemia. For this discipline to be an optimistic alternative in the treatment of various diseases, is responsibility of the medical teams to establish the limits and ethical standards of the advances in genetic manipulation and use of mesenchymal cells. Likewise, must be acknowledged that when it comes to being parents, there is no limit to any attempt to improve the quality and life expectancy of the children.

\section{Conclusion}

Regenerative therapy with stem cells in neonatology is faced with the lack of solid evidence to support its use in terms of efficacy and safety necessary for its therapeutic use. However, ongoing research is promising in proposing a treatment modality aimed at recovering anatomically and functionally tissue, organs and, systems, all of them leading to chronic diseases. Further research is required at this regard. For these reasons, conservative behavior is recommended when advising the parents in order to do not create false expectations. The last is essential considering the explosive increase of companies that offer the "miraculous cure" based on MSC.

\section{Acknowledgment}

None

\section{Conflict of interest}

Authors declare no conflict of interest.

\section{References}

1. O'Reilly M, Thébaud B. Stem Cells for the Prevention of Neonatal Lung Disease. Neonatology. 2015;107:360-364.

2. Lanfranchi A, Porta F, Chirico G. Stem cells and the frontiers of neonatology. Early Hum Dev. 2009;85(10 Suppl):S15-18.

3. Oyarzún E. Células madres: nuevas fronteras para la medicina. Rev Chil Obstet Ginecol. 2005;70(4):211-212.

4. Salinas H, Adauy A, Ide R. Reflexiones acerca de células troncales obtenidas mediante la utilización de embriones humanos. Rev Chil Obstet Ginecol. 2005;70(4):264-271.

5. Meng F, Meliton A, Moldobaeva N, et al. Asef mediates HGF protective effects against LPSinduced lung injury and endothelial barrier dysfunction. Am J Physiol Lung Cell Mol Physiol. 2015;308(5):L452L463.

6. Ramalho-Santos M, Willenbring H. On the origin of the term "stem cell". Cell Stem Cell. 2007;1(1):35-38.

7. Caplan AI. Mesenchymal stem cells. J Orthop Res. 1991;9(5):641-650.

8. Nartprayut K, U-Pratya Y, Kheolamai P, et al. Cardiomyocyte differentiation of perinatally derived mesenchymal stem cells. Mol Med Rep. 2013;7(5):1465-1469.

9. Li D, Chai J, Shen C, Han Y, et al. Human umbilical cord-derived mesenchymal stem cells differentiate into epidermal-like cells using a novel co-culture technique. Cytotechnology. 2014;66(4):699-708.

10. Wu KH, Zhou B, Lu SH, et al. In vitro and in vivo differentiation of human umbilical cord derived stem cells into endothelial cells. $J$ Cell Biochem. 2007;100(3):608-616.
11. Leite C, Silva NT, Mendes S, et al. Differentiation of human umbilical cord matrix mesenchymal stem cells into neural-like progenitor cells and maturation into an oligodendroglial-like lineage. PLOS ONE. 2014;9(10):e111059.

12. Yan ZJ, Hu YQ, Zhang HT, et al. Comparison of the neural differentiation potential of human mesenchymal stem cells from amniotic fluid and adult bone marrow. Cell Mol Neurobiol. 2013;33(4):465-475.

13. Mendez JJ, Ghaedi M, Steinbacher D, et al. Epithelial cell differentiation of human mesenchymal stromal cells in decellularized lung scaffolds. Tissue Eng Part A. 2014;20(11-12):1735-1746.

14. Huang $\mathrm{K}$, Kang $\mathrm{X}$, Wang $\mathrm{X}$, et al. Conversion of bone marrow mesenchymal stem cells into type II alveolar epithelial cells reduces pulmonary fibrosis by decreasing oxidative stress in rats. Mol Med Rep. 2015;11(3):1685-1692.

15. Cerrada A, de la Torre P, Grande J, et al. Human decidua-derived mesenchymal stem cells differentiate into functional alveolar type II-like cells that synthesize and secrete pulmonary surfactant complexes. PLoS ONE. 2014;9(10):e110195.

16. Struebe L, Thebaud B. Advances in bronchopulmonary dysplasia. Expert Rev Respir Med. 2014; 8(3):327-338.

17. O'Reilly M, Thebaud B. Using cell-based strategies to break the link between bronchopulmonary dysplasia and the development of chronic lung disease in later life. Pulm Med. 2013;2013:874161.

18. Borghesi A, Cova C, Gazzolo D, et al. Stem cell therapy for neonatal diseases associated with preterm birth. J Clin Neonatol. 2013;2(1):1-7.

19. Lee JW, Fang X, Krasnodembskaya A, et al. Concise review: mesenchymal stem cells for acute lung injury: role of paracrine soluble factors. Stem Cells. 2011;29(6):913-919.

20. Phillips AW, Johnston MV, Fatemi A. The potential for cell-based therapy in perinatal brain injuries. Transl Stroke Res. 2013; 4(2):137-148.

21. Fung ME, Thebaud B. Stem cell-based therapy for neonatal lung disease: it is in the juice. Pediatr Res. 2014;75(1-1):2-7.

22. Kotton DN, Morrisey EE. Lung regeneration: mechanisms, applications and emerging stem cell populations. Nat Med. 2014; 20(8):822-832.

23. Stabler CT, Lecht S, Lazarovici P, et al. Mesenchymal stem cells for therapeutic applications in pulmonary medicine. $\mathrm{Br}$ Med Bull. 2015;115(1):45-56

24. van Haaften T, Byrne R, Bonnet S, et al. Airway delivery of mesenchymal stem cells prevents arrested alveolar growth in neonatal lung injury in rats. Am J Respir Crit Care Med. 2009;180(11):1131-1142.

25. Pluchino S, Cossetti C. How stem cells speak with host immune cells in inflammatory brain diseases. Glia. 2013;61(9):1379-1401.

26. Ribeiro CA, Salgado AJ, Fraga JS, et al. The secretome of bone marrow mesenchymal stem cells-conditioned media varies with time and drives a distinct effect on mature neurons and glial cells (primary cultures). $J$ Tissue Eng Regen Med. 2011;5(8):668-672.

27. Glenn JD, Whartenby KA. Mesenchymal stem cells: emerging mechanisms of immunomodulation and therapy. World J Stem Cells. 2014;6(5):526-539.

28. Krause B, Castro-Rodríguez J, Uauy R, et al. Conceptos generales de epigenética: proyecciones en Pediatría. Rev Chil Pediatr. 2016;87(1): $4-10$ 